See discussions, stats, and author profiles for this publication at: https://www.researchgate.net/publication/305716254

\title{
Comparative study of Bone tissue accelerated regeneration by latex membranes from Hevea brasiliensis and Hancornia speciosa
}

\section{Article · July 2016}

DOI: 10.1088/2057-1976/2/4/045007

\section{CITATIONS}

7

11 authors, including:

Juliana Ferreira Floriano

São Paulo State University

13 PUBLICATIONS 73 CITATIONS

SEE PROFILE

Edson Luiz Furtado

São Paulo State University

193 PUBLICATIONS 936 CITATIONS

SEE PROFILE
192



Some of the authors of this publication are also working on these related projects:

Leishmania View project

NEW HETEROLOGOUS FIBRIN SEALANT AS BIOLOGICAL SCAFFOLD CANDIDATE FOR STEM CELLS View project 
Comparative study of bone tissue accelerated regeneration by latex membranes from Hevea brasiliensis and Hancornia speciosa

This content has been downloaded from IOPscience. Please scroll down to see the full text. 2016 Biomed. Phys. Eng. Express 2045007

(http://iopscience.iop.org/2057-1976/2/4/045007)

View the table of contents for this issue, or go to the journal homepage for more

Download details:

IP Address: 186.207.249.52

This content was downloaded on 28/07/2016 at 15:50

Please note that terms and conditions apply. 


\title{
Biomedical Physics \& Engineering Express
}

\section{PAPER}

CrossMark

\section{Comparative study of bone tissue accelerated regeneration by latex membranes from Hevea brasiliensis and Hancornia speciosa}

ACCEPTED FOP PUBUICATION

16 June 2016

PUBLISHED

27 July 2016

\author{
Juliana Ferreira Floriano ${ }^{1}$, Fausto Capuano Neto $^{2}$, Lígia Souza Lima Silveira da Mota ${ }^{3}$, \\ Edson Luiz Furtado ${ }^{4,10}$, Rui Seabra Ferreira ${ }^{5,6}$, Benedito Barraviera ${ }^{5,6}$, Pablo José Gonçalves ${ }^{7}$, \\ Luciane Madureira de Almeida ${ }^{8}$, Felipe Azevedo Borges ${ }^{9}$, Rondinelli Donizetti Herculano ${ }^{9}$ and \\ Carlos Frederico de Oliveira Graeff ${ }^{1}$ \\ 1 Department of Physics, Júlio de Mesquita Filho State University of São Paulo, Bauru (SP), Brazil \\ 2 Department of Tropical Diseases, Júlio de Mesquita Filho State University of São Paulo, Botucatu (SP), Brazil \\ 3 Department of Genetics, Júlio de Mesquita Filho State University of São Paulo, Botucatu (SP), Brazil \\ ${ }_{4}$ Department of Plant Protection, Júlio de Mesquita Filho State University of São Paulo, Botucatu (SP), Brazil \\ 5 Department of Tropical Diseases and Diagnostic Imaging, Júlio de Mesquita Filho State University of São Paulo, Faculty of Medicine, \\ Botucatu (SP), Brazil \\ 6 Center for the Study of Venoms and Venomous Animals (CEVAP), Júlio de Mesquita Filho State University of São Paulo, Botucatu (SP), \\ Brazil \\ 7 Institute of Physics, Federal University of Goiás, Goiânia (GO), Brazil \\ 8 State University of Goiás, Ipameri (GO), Brazil \\ 9 Biomaterials Group, Chemistry Institute Júlio de Mesquita Filho State University of São Paulo, Araraquara (SP), Brazil \\ 10 CNPq scholarship holder. \\ E-mail: juli@ibb.unesp.br
}

Keywords: Hevea brasiliensis, Hancornia speciosa, membrane, bioactivity, bone regeneration

Supplementary material for this article is available online

\begin{abstract}
Bone loss is a common problem after accidental traumas, cancers, congenital defects, and surgical procedures. The techniques normally used in large bone restoration involve complex and invasive procedures such as grafting. Thus, it is of interest to develop alternatives such as bioactive materials to induce accelerated bone regeneration. Natural rubber (NR) membranes are potential candidates due to their characteristics such as biocompatibility, angiogenic potential, flexibility, mechanical stability, surface porosity, and permeability. The present study aims at assessing the osteogenic potential of NR membranes of clones of high bioactivity of Hevea brasiliensis (RRIM 600 and IAN 873) and of Hancornia speciosa, as well as Physicochemical characterization at the NR membranes by scanning electron microscopy, Fourier transform infrared spectroscopy, and tensile tests. Critical-size bone defects were surgically made in adult male rabbit calvarium. A fibrin sealant (FS) was used to fix the membranes as a replacement for cyanoacrylate. We compared the respective osteogenic potentials of the tested membranes against a control group in healthy animals. The new bone formed was characterized using radiography, $\mathrm{x}$-ray tomography, and histological and morphometric studies. Our results show that both membranes have great potential for regenerating bone tissue, with higher bioactivity compared to the gold standard (PTFE), which was used as positive control. In both NR membranes the stress-strain profile shows low stress at small strain, characteristic of elastomer with a low degree of reticulation, followed by an increase in the stress at high deformation and two main differences between both NRL biomembranes, related to its composition. The FS acted satisfactorily in the tests, being highly recommended as a substitute for cyanoacrylate in this type of application.
\end{abstract}

\section{Introduction}

Large osseous defects resulting from traumas, cancers, congenital defects, or surgical procedures pose significant reconstructive problems. Generally, bone reconstruction is made through bone grafts or implants [1]. Artificial materials implanted into bone defects are generally encapsulated by fibrous tissue, 
leading to their isolation from the surrounding bone. However, bioactive materials spontaneously bond to living bone without the formation of surrounding fibrous tissue [2]. In recent years, new techniques have been developed to stimulate bone reconstruction [3], which obtained excellent results, since bone tissue has a high regeneration potential with structural organization similar to native tissue. In particular, the use of latex or natural rubber (NR) membranes obtained from the sap of the rubber tree (Hevea brasiliensis) has shown high osteogenic potential [4]. This is due to its characteristics of biocompatibility and high angiogenic potential, as well as the flexibility and mechanical stability, surface porosity, and permeability of the biomembranes [5, 6].

These characteristics of NR membranes allow their performance as an occlusive mechanical barrier, hampering the migration of cells incompatible with the formation of new tissue, preventing competition with tissues of greater proliferative capacity and favoring osteogenesis [7]. Moreover, NR membranes can also act as a source of gradual release of substances with osteogenic potentials [8,9]. Different studies have shown that these membranes integrate gradually into the bone, generate an acceleration of the bone formation, and improve the cicatrization process [10]. In this way, the use of NR membrane provides great benefits for human health, preventing many difficulties such as bone transplants and grafts. Another great advantage of the use of these membranes is their low cost, since they can be produced on a large scale, being a biomaterial accessible to all [11]. The bioactivity of the latex origin is still unknown, since it has a large genetic variability. It is believed that there are clones of Hevea brasiliensis that produce latex with the greatest bioactive potential. In our previous work, we showed some preliminary evidence about this fact. In this paper, we compare two clones with the highest potential, in in vivo tests [5].

Latex allergy from Hevea brasiliensis is a recurring scientific topic. It is well documented that NR can cause allergic reactions in humans; it may in part be related to the latex processing [12]. In our previous work [5], we used a method of collecting and processing NR membranes without the use of any chemical additive that can cause allergy, where no negative responses were verified that indicate an allergic process. These results are consistent with other studies in the literature that conclude that NR membranes do not causes an allergic reaction and induce inflammatory responses similar to a normal healing process [13]. Thus, it is of great interest to search for other lactiferous species that can produce bioactive latex with low allergenic potential.

The latex obtained from Hancornia speciosa, a plant native to Brazil, typically found in the Amazon Rainforest and in the Caatinga and Cerrado vegetation, may be an interesting alternative for biomembrane production for medical application. The low protein content of Hancornia, when compared to Hevea, is one of the most remarkable findings of Malmonge et al, indicating that Hancornia speciosa has the potential to have fewer allergic components. For this reason, in this work we use Hancornia speciosa latex membranes in order to compare their potential with rubber latex membranes, in in vivo studies of bone regeneration, in search for an alternative to atopic patients [14].

Among the existing methods to assess the bone regeneration potential of a new material, such as NR membranes, the model of a calvarial critical-size defect (CSD) is widely accepted in the scientific community. It has the advantage, unlike other models, of being based on a defect size specifically large enough to heal bone tissue, thus minimizing the difficulties due to differences in age, species, and anatomical place [15, 16]. Moreover, the association of a CSD with image analysis techniques, such as radiography and computed tomography (CT), which permit the monitoring of the evolution of the process of new bone formation, allows a precise assessment of the newly formed bone stimulated by the material to be tested $[17,18]$.

The present study aims at assessing the osteogenic potential of the rubber tree latex membranes of the RRIM 600 and IAN 873 clones, and of Hancornia speciosa latex membranes, using the CSD method. The RRIM 600 and IAN 873 clones were selected to present high bioactivity, as reported in a previous study [5]. Hancornia speciosa latex, in turn, has good angiogenic activity [19] and may be an alternative to rubber tree latex for atopic patients. Another innovation of this study was to fix the membranes to the bone on the CSD by means of a fibrin sealant (FS), a kind of biological glue derived from snake venom, as a substitute for cyanoacrylate, a material commonly used, but presenting innumerable negative responses [20,21].

\section{Materials and methods}

\subsection{Membrane preparation}

NR membranes were produced from latex collected from two different clones, RRIM 600 and IAN 873. RRIM 600 trees are grown at Balsam Farm (HeveaTec group), located in Nhandeara in the State of São Paulo. The membranes made of this clone were named NRr1. The IAN 873 trees were grown on a farm belonging to the State University of São Paulo-UNESP, at Lageado Farm in Botucatu, the State of São Paulo. The membranes made from this clone were named NR-r2. The latex collection was carried out in the morning by making a half-spiral cut $(1 / 2 \mathrm{~S})$. The collected serum was stored at low temperatures to prevent spontaneous coagulation. The collecting bowl was filled with ice, and a sterilized $200 \mathrm{ml}$ glass bottle was placed in its center. The serum was centrifuged for $5 \mathrm{~min}$ at $1500 \mathrm{rpm}$ to remove impurities gathered during the collection process. The membranes were produced 
within a laminar flow hood by pouring about $6.5 \mathrm{ml}$ of the serum onto a polystyrene $60 \times 15 \mathrm{~mm}$ Petri dish and carried to an oven, where they were dried at $50{ }^{\circ} \mathrm{C}$ and remained for $48 \mathrm{~h}$ to complete the polymerization.

The Hancornia speciosa NR membranes (NR-h) were produced with latex collected from a farm belonging to the State University of Goiás in Ipameri the State of Goiás. The latex was collected in a sterilized container by a knife incision in the bark. The cut was approximately $10 \mathrm{~cm}$ long and $0.5 \mathrm{~cm}$ deep [19]. Distilled water was added in a ratio of about 1:1 (latex: water) to prevent coagulation. The latex was centrifuged for $5 \mathrm{~min}$ at $3500 \mathrm{rpm}$ to remove impurities gathered during the collection process. The membranes were prepared by pouring about $10 \mathrm{ml}$ of serum onto a Petri dish $(10.00 \pm 0.05 \mathrm{~cm}$ in diameter). Typically, they were left for 3 days at $55^{\circ} \mathrm{C}$ to complete the polymerization.

The NR membranes were sterilized at the Instituto de Pesquisas Energéticas Nucleares (IPEN-Brazil) by gamma radiation performed in a Gammacell 220, with a cobalt source $\left(\mathrm{Co}^{60}\right)$, and a dose of $25 \mathrm{kGy}$ [22].

\subsection{Physicochemical characterization}

\subsubsection{Scanning electron microscopy (SEM)}

For SEM the membranes were fixed in $2.5 \%$ glutaraldehyde for $24 \mathrm{~h}$. After the initial fixation, the material was washed 3 times in $0.1 \mathrm{M}$ phosphate buffer with a $\mathrm{pH}$ of 7.3, 5 min apart, and post-fixed in 1\% osmium tetroxide in the same buffer for 30 min Dehydration was performed using ethyl alcohol and liquid $\mathrm{CO}_{2}$. The specimens were glued onto a suitable support and coated with a gold layer $20 \mathrm{~nm}$ thick using a thermal evaporator, Balzer model 010. The SEM images were formed in a Philips microscope model 515.

\subsubsection{Fourier transform infrared spectroscopy (FTIR)}

An attenuated total-reflectance Fourier transform infrared spectrometer (ATR-FTIR, Tensor 27, Bruker) equipped with a diamond-coated ATR crystal was used to characterize the chemical composition. ATRFTIR was performed at a resolution of $4 \mathrm{~cm}^{-1}$, averaging 16 scans over a range of $4000-380 \mathrm{~cm}^{-1}$.

\subsubsection{Mechanical tests}

Tensile tests on the specimens were carried out on a DL-2000 (EMIC) testing machine, with a $50 \mathrm{kgf}$ load cell at a speed of $500 \mathrm{~mm} \mathrm{~min}^{-1}$ and elongated until failure. The values were converted to stress-strain curves and the Young's modulus was calculated from the initial linear part ( $0 \%-5 \%$ elongation).

\subsection{In vivo experiments}

The critical-size calvarial defect (CSD) is commonly used to assess biomaterials promoting bone tissue growth [16]. A CSD is defined as the smallest size intra-osseous wound that will not heal spontaneously.
It was originally developed as a model of non-ligated craniofacial fibrosis, and was conceived to standardize the testing of bone repairing materials that may be used as alternatives to bone implants [23-25].

To assess the osteogenic potential of the NR membranes, we used 60 New Zealand race adult male rabbits, which were randomly distributed into 2 groups depending on the implantation period of 60 or 90 days, and subdivided into 5 treatment groups, each group containing 6 animals. 3 groups received NR membrane implants, and there was 1 positive control group and 1 negative control group during each test period. The animals were treated in accordance with the Ethical Principles for Animal Research adopted by the Brazilian College of Animal Experimentation (COBEA). During this research, the use of animals followed all the current ethical norms, and it was approved by the Ethics Commission of the State University of São Paulo-UNESP, on 11 January, 2009, protocol number 2612/46/01/08.

The FS derived from snake venom was kindly supplied by the Center for the Study of Venoms and Venomous Animals (CEVAP) of the UNESP; its constituents and instructions for use are stated in patents BR1020140114327 and BR1020140114360, and was used in this study for the fixation of the NR membranes in the CSD. At the time of use, the components had been previously thawed, reconstituted, mixed, and applied. For more detail see [26].

For the surgical procedures, the animals were sedated with acepromazine $\left(0.1 \mathrm{mg} \mathrm{kg}^{-1}\right)$ and butorphanol $\left(0.1 \mathrm{mg} \mathrm{kg}^{-1}\right)$, injected intravenously, and 15 min later, anesthetized with a combination of tiletamine-zolazepam $\left(10 \mathrm{mg} \mathrm{kg}^{-1}\right)$ and xylazine $\left(0.5 \mathrm{mg} \mathrm{kg}^{-1}\right)$, administered intramuscularly.

After trichotomy of the frontal bone region, the rabbits were placed in ventral decubitus, and the antisepsis of the surgical site was performed with povidone-iodine and physiological solution. After placing the operative-field sheets, an incision was made in the skin and subcutaneous tissue, extending itself along the middle line from the external protuberance of the occiput to the eye level. The frontal, interscutular, and occipital muscles were incised, moved away with a rugine, and retracted to show the periosteum of the parietal bone. Then we created a circular, critical-sized defect about $2 \mathrm{~cm}$ in diameter with a trephine $1 \mathrm{~cm}$ in diameter, activated by a surgical micromotor and abundant irrigation with $0.9 \%$ saline solution. Two holes were made, which were joined with the help of a luer forceps, making one defect. All the procedures was carried out carefully to preserve the dura-mater membrane. The cortical and spongy bone was removed, showing the meningeal membrane. In the groups treated with the NR membranes, the defect was occluded with a membrane fragment measuring about $2 \mathrm{~cm}$. On this membrane and also on the edge of the defect, we deposited about $1 \mathrm{ml}$ of the FS to fix the second membrane fragment, which was placed in order 
to cover the defect. As a negative control the defect was filled with fibrin clot [7], and as a positive control the defect was filled with PTFE membranes [27, 28].

The periosteum and muscles close to the defect were moved closer with a continuous suture, the subcutaneous tissue with an invaginating suture and the skin with stitches. The threads used were 3-0 and 4-0 nylon.

Before anesthetic induction and $24 \mathrm{~h}$ after the surgical procedure, enrofloxacin at a dose of $5 \mathrm{mg} \mathrm{kg}^{-1}$ was injected intramuscularly. Flunixin meglumine $\left(1 \mathrm{mg} \mathrm{kg}^{-1}\right)$ was administered subcutaneously every $24 \mathrm{~h}$ during immediate post-surgery and for three more days. The surgical wounds were treated with povidone-iodine and the cutaneous stitches were removed on the 10th day after surgery.

At the end of the period of 60 and 90 days, the animals were euthanized with pentobarbital ( $>100 \mathrm{mg} \mathrm{kg}^{-1}$ intravenously), after anesthesia with ketamine and xylazine. After euthanasia, the animals were placed in the ventral decubitus position and a new trichotomy was performed; any alterations in the regions close to the defect were annotated. A vertical incision was made close to the defect with a margin of about $1 \mathrm{~cm}$ around it. After collection the pieces were fixed in 10\% formaldehyde for analysis.

\subsection{X-ray imaging}

After 30 days, radiographic images of the implanted animals were made using a GE OPTIMA XR 220AMX equipment set at $70 \mathrm{kVp}, 8 \mathrm{~mA}$, and $2 \mathrm{mAs}$. The $\mathrm{x}$-ray sensor was positioned $40 \mathrm{~cm}$ from the focus tube. After euthanasia (60 and 90 days), the collected pieces were also subjected to radiography.

The CT images of the pieces collected after euthanasia were obtained using a Shimadzu SCT-7000 model, imagine planes were taken every $1 \mathrm{~mm}$ and $1 \mathrm{~s}$ (1:1), using a potential of $120 \mathrm{KV}$ and a current of $50 \mathrm{~mA}$. The bone density was estimated with E-Film Workstation 4.0.3 software (Merge Healthcare Incorporated, Chicago, CA, USA) using a Hounsfield unit (HU) $[15,29]$.

\subsection{Tissue processing and histological analyses}

The collected pieces in 10\% formaldehyde for $24 \mathrm{~h}$ were included in paraffin. The pieces were then cut and at least 4-6 laminas were examined per animal. The $5 \mu \mathrm{m}$ thick histological sections were stained with Masson trichrome for histological analysis, which consists in the assessment of the osteogenic process, the evolution of the bone defects made in the calvaria of the rabbits, and the construction of a widescreen to display the defect repair process.

\subsection{Histomorphometric analysis}

The histomorphometric analysis was assessed by the traditional Weibel method [30], in which one uses a test system of lines and points on a 168-point graticulate. The bone volume $(N)$ of each lamina was calculated using the formula:

$$
N=\frac{\operatorname{Lm}}{168} \times 100
$$

where Lm matches the mean linear intercept (in $\mu \mathrm{m}$ ). Therefore, this method allows the calculation of the bone volume found on the lamina analyzed as a percentage calculation. In this work, 10 fields of 5 histological laminas were analyzed per group, the analyzed places being randomly chosen within the region of the bone defects. The images of the sections were digitized for analysis [31].

\subsection{Statistical analysis}

Statistical analysis was performed using the Jandel Sigma Stat program (Jandel Corporation, San Rafael, CA, USA). The results of the CT bone density and morphometry were analyzed using ANOVA or Kruskal-Wallis with a significance set at $P<0.05$.

\section{Results}

\subsection{Physicochemical characterization}

A tensile test was performed to compare the mechanical behavior of both the NR membranes, and in all samples good reproducibility was obtained, indicating homogeneity. Figure 1 shows that both NRLs present elastomeric behavior, with high elongation and a low Young's modulus. The NRL from Hevea brasiliensis appeared to be stiffer than the NRL from Hancornia speciosa due to a higher Young's modulus, and more resistant with higher elongation and stress at rupture, as shown in table 1 .

Table 1 resumes the results of the tensile mechanical test. The low values for the Young's modulus are due to the non-vulcanization usually employed for NR latex.

Figure 2 shows that, in terms of molecular structure, both NRL membranes are composed of the polymer cis-1,4-polyisoprene. The band around $3040 \mathrm{~cm}^{-1}$ is assigned to $=\mathrm{CH}$ stretching of between $2963 \mathrm{~cm}^{-1}$ and $2845 \mathrm{~cm}^{-1}$, to $\mathrm{CH}_{3}$ and $\mathrm{CH}_{2}$ stretching of $1658 \mathrm{~cm}^{-1}$, to $\mathrm{C}=\mathrm{C}$ stretching of $1445 \mathrm{~cm}^{-1}$ and $1374 \mathrm{~cm}^{-1}$, to $\mathrm{CH}_{2}$ and $\mathrm{CH}_{3}$ deformation, respectively; $837 \mathrm{~cm}^{-1}$ to $=\mathrm{CH}$ out-of-plane bending, $567 \mathrm{~cm}^{-1}$ and $488 \mathrm{~cm}^{-1}$ to $\mathrm{C}-\mathrm{C}-\mathrm{C}$ deformation. The FTIR spectra agreed well with the literature and the theoretical calculation of the vibrations (vibrational spectra of cis-1,4-polyisoprene). The absence of the band in the $960-970 \mathrm{~cm}^{-1}$ range and the presence at $837 \mathrm{~cm}^{-1}$ confirmed the cis-configuration and not trans. The assignments are summarized in table 2.

Figure 3 shows that all the NR membranes present high surface porosity, as noted in the SEM micrographs, where it is also possible to observe cells that have adhered to the surface. The cells show to be adhered to the NR surface with a spread and flat morphology (figures 1(a) and (b)). The inset shows the 


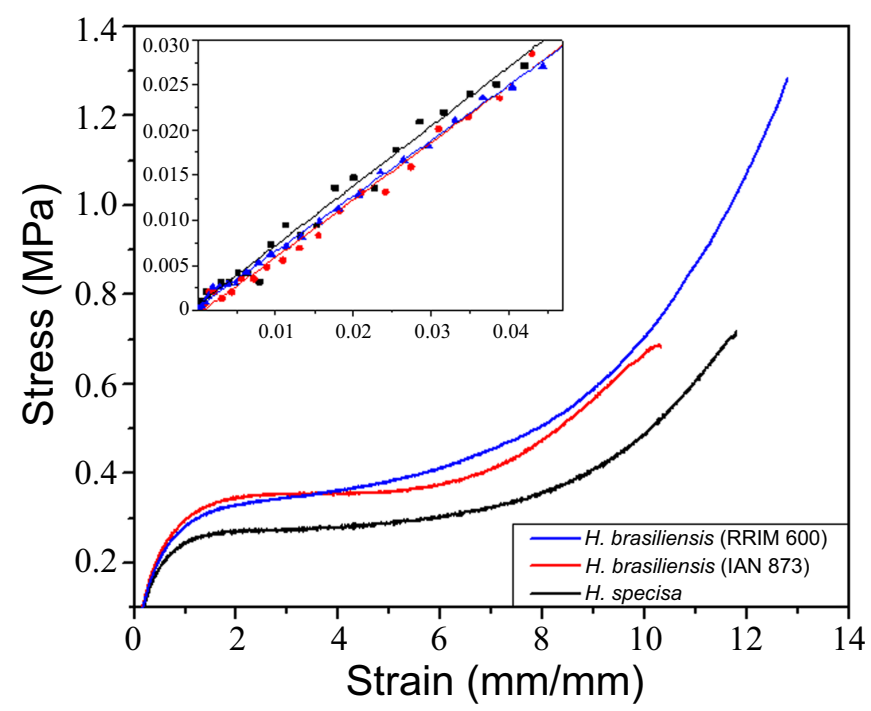

Figure 1. Stress-strain curve of the NR membranes from Hevea brasiliensis (RRIM 600), Hevea brasiliensis (IAN 873), and Hancornia speciosa. The inset shows the initial linear part of the stress-strain curves.

Table 1. Average value and standard deviation of the strain at break, ultimate tensile, and Young's modulus from NRLs from different sources.

\begin{tabular}{lccc}
\hline & Strain at break (\%) & Ultimate tensile strength (MPa) & Young's modulus (MPa) \\
\hline Hevea brasiliensis (RRIM 600) & 1278.82 & 1.28 & 0.61 \\
Hevea brasiliensis (IAN 873) & 1031.38 & 0.68 & 0.63 \\
Hancornia speciosa & 1178.17 & 0.71 & 0.66 \\
\hline
\end{tabular}

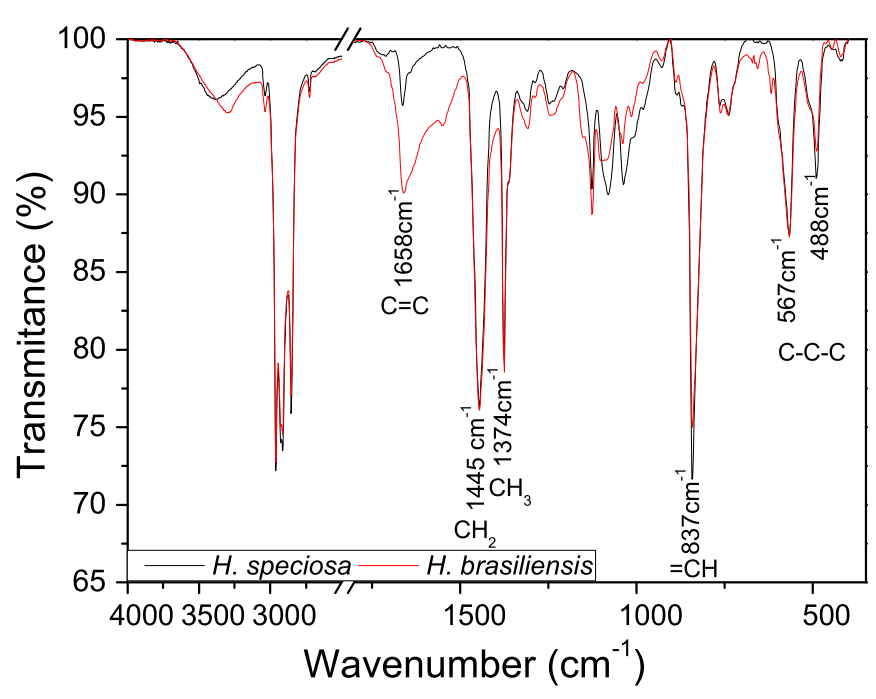

Figure 2. FTIR spectra of NR membranes from Hancornia speciosa and Hevea brasiliensis.

contact between the cell and surface in a higher magnification.

\subsection{Radiographic analysis}

Figure 4 shows the radiography images of the implanted animals. Figures 4(a) and (b) shows the typical evolution of the surgical process after 30 days of operation. All animals with implanted NR membranes showed good evolution during the post-operative period and, within 30 days, it was already possible to observe radiopaque regions at the edges of the defects, see for example the red arrow in figure 4(b). On the other hand, the negative and positive control groups showed no radiopaque region during this testing period (figure 4(a)). Figures 4(c)-(h) shows the typical radiography images. The groups treated with the NRr1 membrane showed newly formed bone, as can be verified by the radiopaque regions in figures 4 (c) and 
Table 2. FTIR assignments of the NR membranes.

\begin{tabular}{ll}
\hline Wavenumber $\left(\mathrm{cm}^{-1}\right)$ & Assignment \\
\hline 3040 & $=\mathrm{CH}$ stretching \\
2963 & Methyl $\mathrm{CH}_{3}$ asymmetric stretching \\
2904 & Methyl $\mathrm{CH}_{3}$ symmetric stretching \\
2845 & Methylene $\mathrm{CH}_{2}$ symmetric stretching \\
1658 & $\mathrm{C}=\mathrm{C}$ stretching \\
1445 & Methylene $\mathrm{CH}_{2}$ deformation \\
1374 & Methyl $\mathrm{CH}_{3}$ asymmetric deformation \\
837 & $=\mathrm{CH}$ out-of-plane bending \\
567 & $\mathrm{C}-\mathrm{C}-\mathrm{C}$ deformation \\
488 & $\mathrm{C}-\mathrm{C}-\mathrm{C}$ deformation \\
\hline
\end{tabular}

(f). Similar results were found in the other NR groups, as can be seen in the supplementary data (S1). In figures $4(\mathrm{e})$ and $(\mathrm{h})$, one can observe that the negative control during both testing periods showed little or no radiopaque area. The positive control showed some radiopaque region, but far less dense than the groups treated with NR, as can be observed in figures 4(d) and (g). In all the radiography, the arrows indicate the radiopaque regions in the CSD.

\subsection{Bone density measured by $\mathrm{CT}$}

Figure 5 presents the CT images of the different animal groups for the period of 60 and 90 days. Figures 2(a) and (b) shows CT images of the group that was treated with NR-r1 membranes. The arrows represent the hyperdense regions observed. It is possible to observe that, during both testing periods, there is a hyperdense lamina in the basal region of the defect. The basal region is where the process of new bone formation starts. Moreover, it is possible to verify the excellent evolution of the process; the hyperdense regions are larger and more homogeneous in the 90 day group. Similar results were found for NR-r2 and NR-h, as shown in the supplementary data (S2). A small hyperdense lamina may be observed in the basal region of the defect in the positive control (figures 5(c) and (d)). If we compare this result with the results of the other tested groups, where the NR-r1,2 and NR-h membranes were used, it is evident that NR is more efficient in bone regeneration. On the other hand, as expected in the negative control group, there is no hyperdense region, showing that the CSD does not regenerate spontaneously.

Figure 5(g) shows the calculated bone density assessed by CT. One can observe that the average HU of the defect in the groups treated with NR-r1,2 and NR-h is higher during both testing periods. During the 90 day period, the density increased significantly, in fact its value is close to the values of the native bone at the defect's edge. In the positive control group, the bone density was not only lower than in the groups treated with NR, it also did not increase throughout the period. In the negative control, on the other hand, no new bone was formed.

\subsection{Histological and histomorphometric analysis} Figures 6(a)-(f) presents the results of the histological analyses of the collected pieces of the groups treated with NR membranes, the positive control (PTFE), and the negative control (clot). In the NR membrane groups and positive control, when compared with the untreated or negative control group, it was possible to verify that, during the 60 day period, there is a large amount of new immature dense bone tissue; showing centripetal bone formation interspersed with bone marrow (indicated as $\mathrm{M}$ in the figure); connective tissue undergoing ossification in abundance (indicated as CT); an increase in the number of osteocytes in the new bone matrix; and the presence of osteoclasts. This is a clear indication of effective new bone formation and the good quality of the newly formed bone (figures 6(a)-(d)). In figure 6(a), which corresponds to the positive control group (treated with PTFE), one can observe some cells permeating the membrane due to its non-occlusive characteristics $[32,33]$. It should be noted that all the treated groups' NR membranes showed similar results; only one image was representative of other membranes due its resemblance.

In the clot group bone formation (indicated with *) the features are restricted due to the adjacent competitive tissue.

Figures 7(a)-(d) shows the same results as figure 6, but for the 90 day groups. In this case, for the groups treated with NR membranes figures (c) and (d) the new bone tissue is mature, its lamellar structure is well organized, it has an abundant presence of osteocytes, but small regions of immature primary bone and connective tissue undergoing ossification, filling a large amount of the lamellar bone trabeculae (blue arrow) interspersed with bone marrow, can be observed. In the positive control group-PTFE (figure 7(b)), on the other hand, there is an island of growth with mature new bone, composed of lamellar secondary new bone and a predominance of immature primary bone. Cells such as osteocytes and connective tissue undergoing ossification permeated the membrane. There are also osteocytes in abundance, and to a lesser extent the presence of immature bone tissue areas with Haversian systems and the presence of mature lamellar bone in the group treated with NR membranes, as shown in figure 8, which presents the polarized-light photomicrograph of the groups tested except for the negative control. One can verify that in all the NR groups the bone organization improves with time. There is clear evidence of secondary bone present in the 90 day NR groups, which present parallel bone lamellae and concentric bone lamellae forming Haversian canals. On the other hand, in the positive control group (figures 6(b1) and (b2)), one can verify that there was no discernible difference in bone organization with the period of implantation. In this case there is an abundance of immature bone tissue during both the tested periods. It should be noted that the negative control group was not shown because similar results 


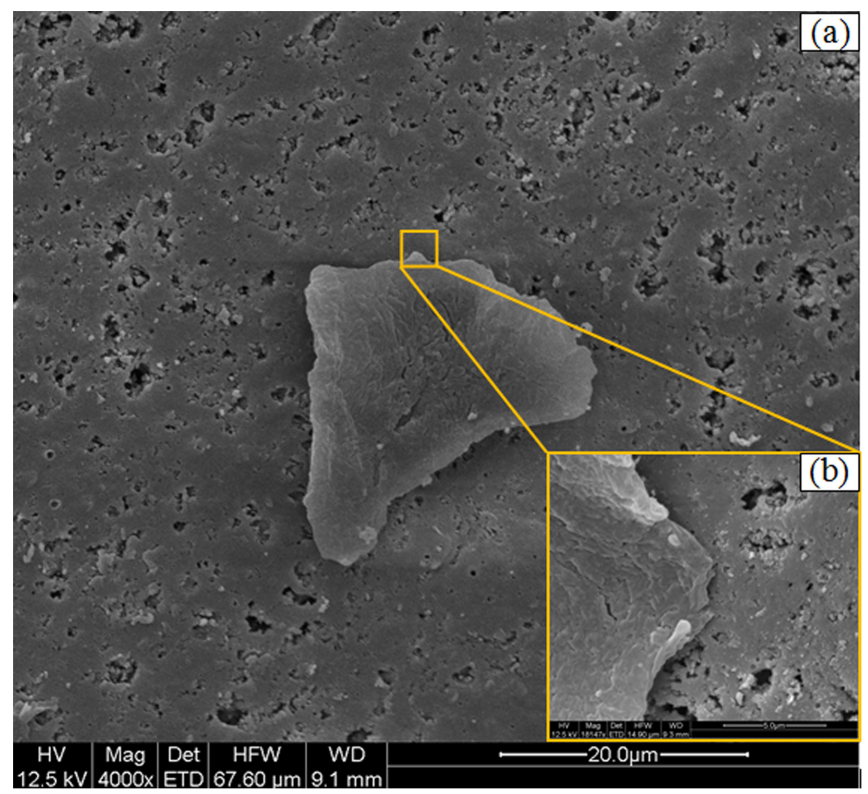

Figure 3. (a) SEM visualization of the NR surface of the RRIM 600 clone, representative of other membranes due its resemblance. (b) The inset shows, with higher magnification, the cell surface contact.

were found during both periods, and due its resemblance only the image is shown.

According to table 3, one can see that, during the first testing period, there was no significant difference in bone volume in all the groups. During the second testing period, there were significant differences between the groups; those treated with latex membranes gaining higher bone volumes than those treated with PTFE. The bone volume of the group treated with PTFE during the second testing period was very similar to the volume presented during the 60 day period.

\section{Discussion}

The NR from Hevea brasiliensis and Hancornia speciosa has been very promising for biological applications and biomaterials because of its important features as a natural stimulation of angiogenesis and biocompatibility [5, 19]. Ferreira et al showed that the NR latex films produced by casting induce vessel growth in the chorioallantoic membrane CAM, and it can be considered as a potential biomaterial [34]. Almeida et al indicated that the latex obtained from Hancornia speciosa and eluted in water presents significant angiogenic activity and does not present cytotoxic or genotoxic effects on the life system [19].

Besides the features mentioned, the NR shows good elasticity and low mechanical hysteresis. A tensile test was performed to compare the mechanical behavior of both NR membranes, and in all the samples good reproducibility was obtained, indicating homogeneity (figure 1). Table 1 resumes the results of the tensile mechanical test. The low values for the Young's modulus are due to the non-vulcanization usually employed for the NR. Valadares et al and Rezende et al also obtained values below $1 \mathrm{MPa}$ with an elongation of $980 \%-1150 \%$ unvulcanized, even using higher temperatures to dry, which may explain their higher values for tensile strength $[35,36]$.

Both NRs showed elastomeric behavior, with high elongation and a low Young's modulus. The NR from Hevea brasiliensis appeared to be stiffer than the NR from Hancornia speciosa due to a higher Young's modulus, and to be more resistant with higher elongation and stress at rupture (table 1). In both biomembranes the stress-strain profile shows low stress at small strain, characteristic of elastomer with a low degree of reticulation, followed by an increase in the stress at high deformation, although Hancornia speciosa were less intense; this abrupt increase in stress is due the strain-induced crystallization. The small differences between the Hevea Brasiliensis membranes may be due the latex clone compositions. Dall'Antonia et al observed differences between RRIM 600 and IAN 873, where IAN 873 presented higher Wallace plasticity and mooney viscosity, indicating a higher polymer chain or more crosslinking. RRIM 600, due its lower values, corroborated with the higher amount of nitrogenous compounds and acetonic extract, which enhances polymer chains' mobility, acting as a plasticizer; it also had a higher percentage plasticity retention index, related to better thermo-oxidative resistance. Thiols are one of those responsible for protecting the latex organelle membrane, but they occupy the active sites for crosslinking, thereby preventing crosslinking, corroborating the differences in mechanical behavior in this work and in the other parameters (seasonal and clonal variations in the latex and raw) [37]. 

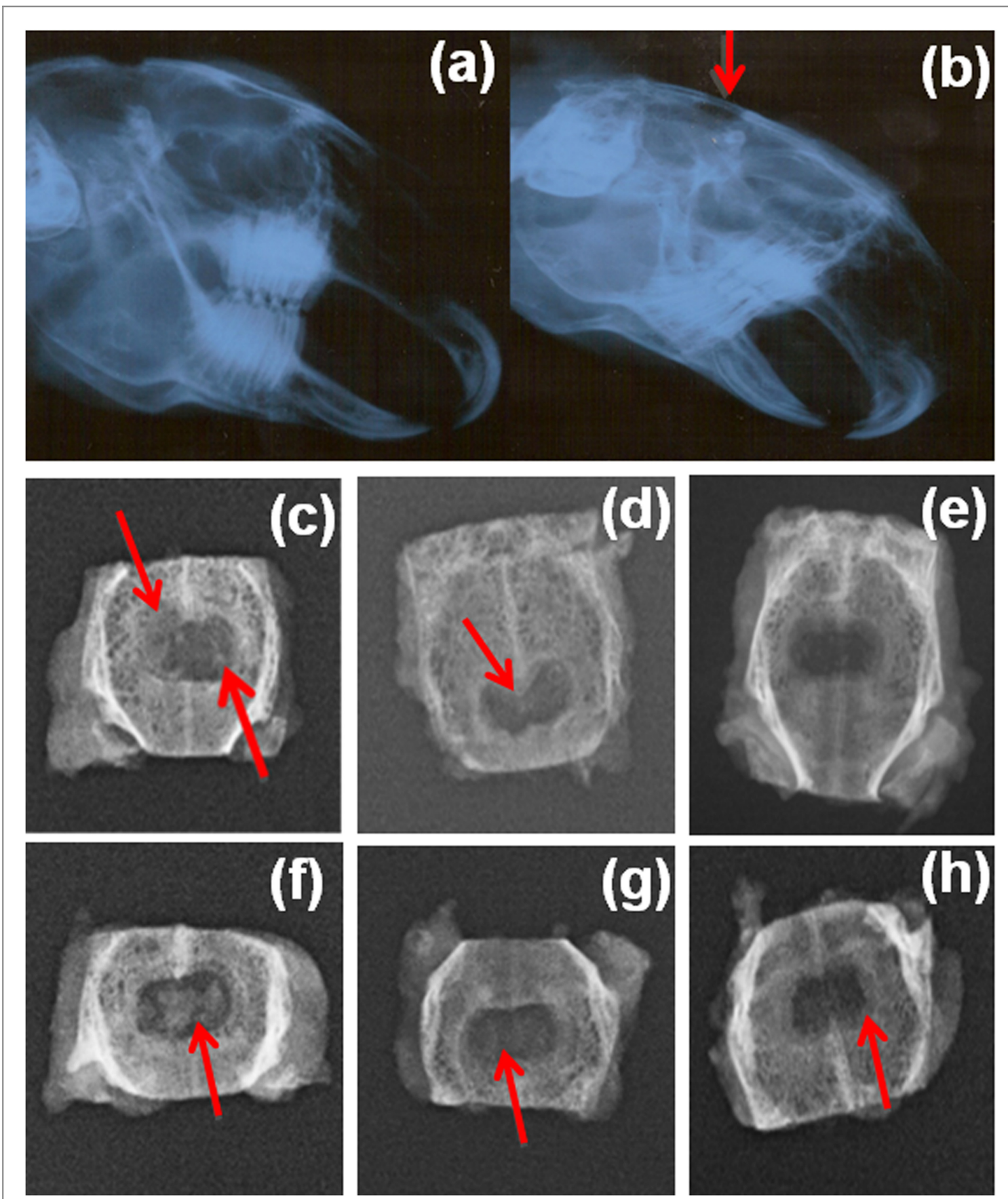

Figure 4. Radiographies of the animals' heads after 30 days of the CSD operation: (a) negative control group (clot) and (b) group treated with NR-r1 membrane. Radiographies of the defect area for the groups of 60 and 90 days: (c) and (f) treated with NR-r 1 membranes, (d) and (g) positive control group (PTFE), (e) and (h) negative control group (clot). In all the radiographies the arrows indicate the radiopaque regions in the CSD.

The differences in tensile behavior may be due the different composition of both rubber particles. The NR extracted from Hevea brasiliensis have a higher protein content; Malmonge et al showed a higher percentage of nitrogen in Hevea brasiliensis $(0.3 \%)$ than in Hancornia speciosa $(0.06 \%)$, which were related to a higher protein content of $32300 \mu \mathrm{g} \mathrm{g}^{-1}$ for Hevea brasiliensis and $1900 \mu \mathrm{g} \mathrm{g}^{-1}$ for Hancornia speciosa. Almeida et al (2014) also observed differences in nitrogen content in both latexes [14, 19]. Malmonge et al also observed differences in acetone extract, which is related to a high lipid content; Hancornia speciosa presented $6.9 \%$ when compared to Hevea brasiliensis $(2.59 \%)$. The rubber particles are stabilized by a phospholipid/protein layer that confers a colloidal stability to the liquid latex; in Hancornia speciosa a higher content of fatty acids may be needed to stabilize due its low amount of protein [14, 38].

The mechanical behavior of the NR from Hancornia speciosa is understudied, although the influence of proteins and fatty acids in the mechanical behavior of the NR from Hevea brasiliensis is well exploited from deproteinized NR (DPNR). Amnuaypornsri et al observed a reduction in elongation and tensile 

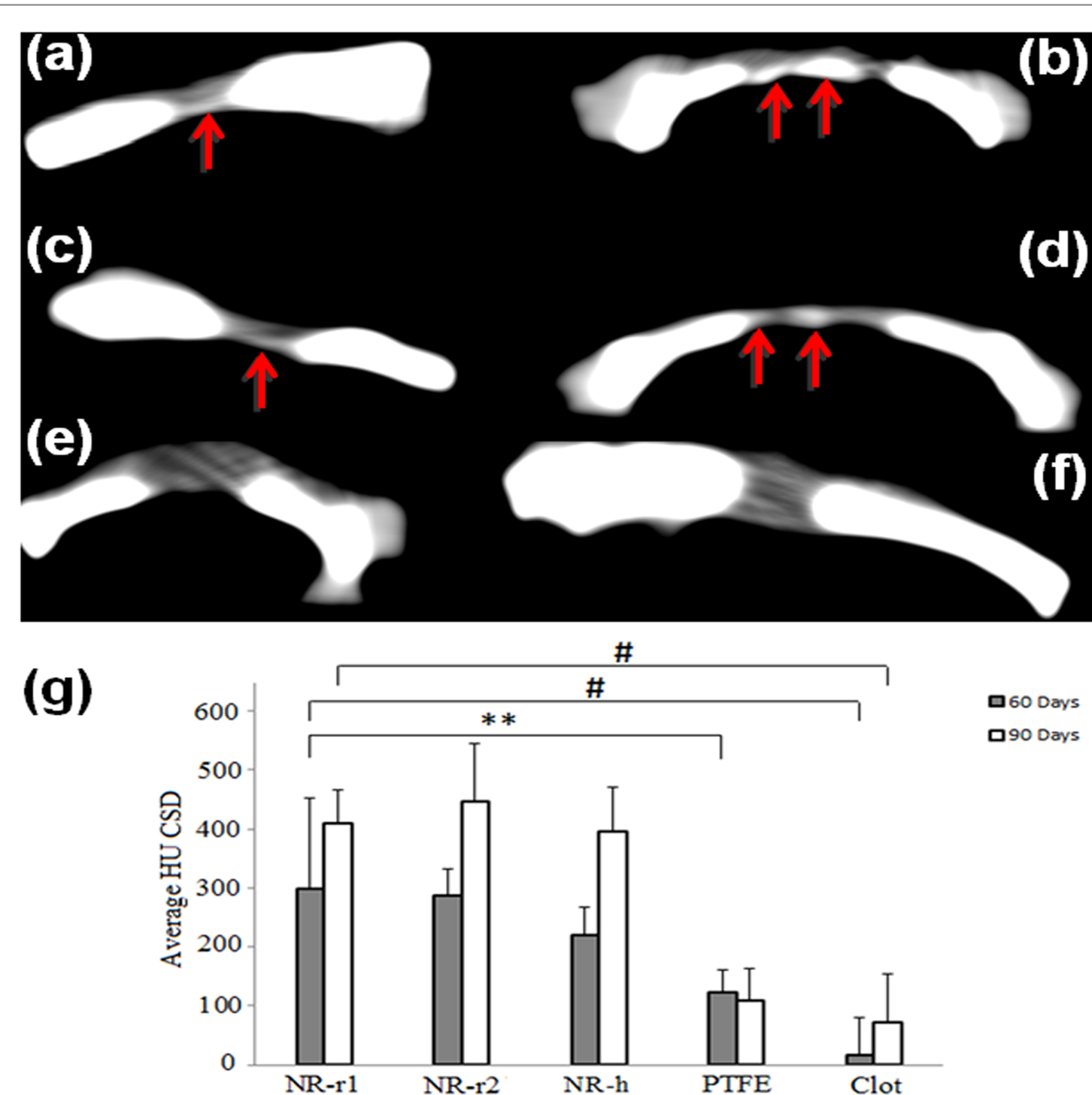

口60 Days 口90 Days

5. CT Images of the CSD region for the 60 and 90 day groups after implantation of the membranes: (a) and (b) group treated with NR-rl membranes, (c) and (d) positive control group (PTFE), (e) and (f) negative control group (clot). In (g) the average bone density of the center of the CSD in all the groups during the 60 and 90 day-periods after implantation, obtained by CT analysis. ${ }^{* *}$ $P<0.05$ all the NR groups versus positive control during the 60 day testing period; \# $P<0.001$ all the NR and positive control groups versus the negative control during the 60 day, and all the NR groups versus the positive control and negative control during the 90 day period; there was no significant difference in the comparison of the NR-r1, 2 groups versus NR-h during both testing periods.

strength [39]. Amnuaypornsri et al observed that, in general, the NR showed higher stress in all the ranges of deformation and higher values of anisotropic fraction than the DPNR, indicating that a naturally occurring network, originated by the interaction of proteins, plays a significant role in the orientation of isoprene molecules and the consequential strain-induced crystallization during deformation [40]. Amnuaypornsri et al observed that the DPNR showed lower strength, but higher strain at break than the NR. The decreases in tensile properties may be attributed to the reduction in branch-points [41].

Other differences were observed in the NR composition derived from each species, as discussed above. From the FTIR (figure 2) two main differences were observed between both NR membranes; the
Hancornia speciosa NR is known to possess higher amount of fatty acids, while Hevea brasiliensis have a higher protein content [14]. In the Hancornia speciosa spectra a more broadened band of around $3500 \mathrm{~cm}^{-1}$ is observed, related to free fatty acids while the Hevea brasiliensis spectra have a band of around $3287 \mathrm{~cm}^{-1}$ and at $1547 \mathrm{~cm}^{-1}$, corresponding to $\mathrm{N}-\mathrm{H}$ stretching and deformation from the amide group, respectively, which are related to its higher protein content [14].

Dall'Antonia et al in the mechanical and thermal characterization of the formulated and vulcanized natural rubber clones: GT 1, IAN 873, PB 235 e RRIM 600 also obtained no differences in FTIR spectra regardless of the type clone studied (GT 1, IAN 873, PB 235 e RRIM 600) [37]. Almeida et al observed similar compositions between both NR membranes from Hevea 


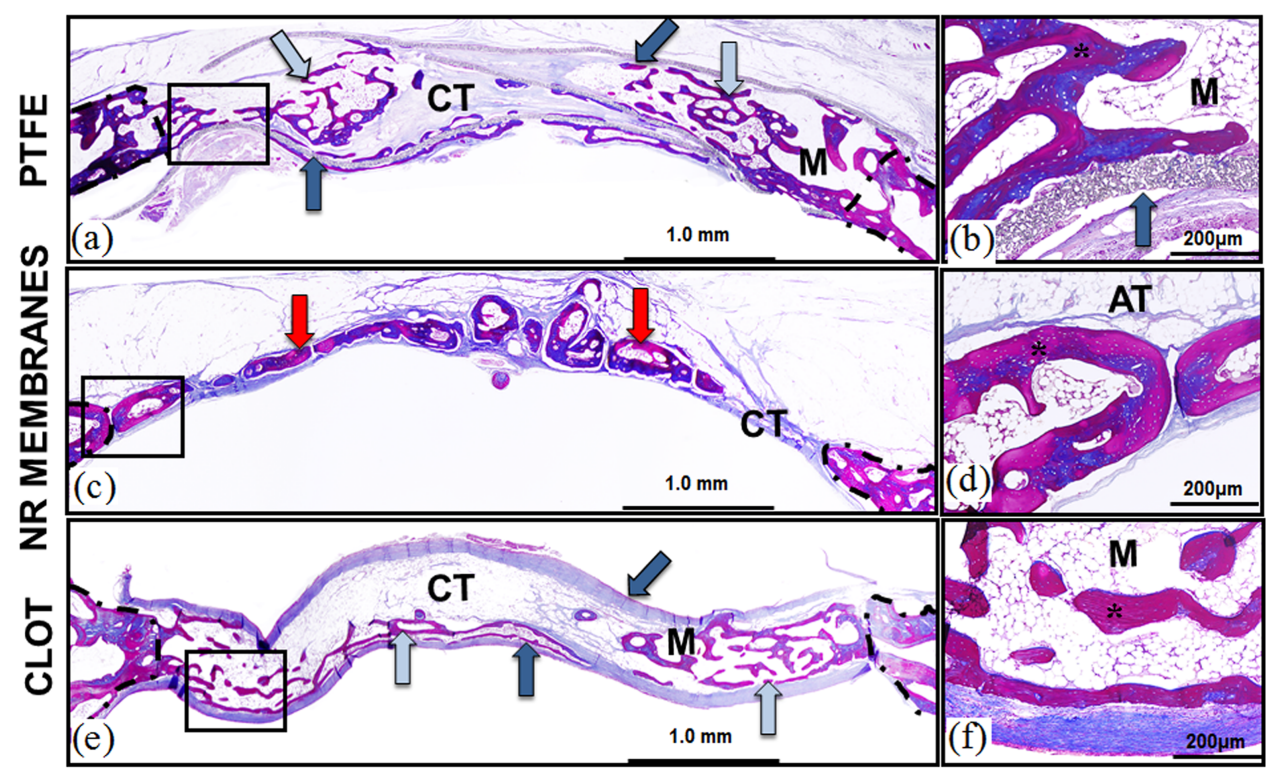

Figure 6. Photomicrographs of the evolution of the bone defect made in the calvaria of the rabbits treated with the positive control (PTFE), NR membranes, and negative control (clot) (figures (a)-(f)) for 60 days. Figures (a), (c), and (e) widescreen aspect centripetal exhibiting bone formation interspersed with bone marrow (M) to areas of connective tissue (CT) located predominately in the central region of the defect. Note on the repair of the groups treated with PTFE membranes (figure (a)) and Latex (figure (c)) the defective area of the insulation (green arrow), allowing the growth of bone tissue (blue arrow) towards the dural region-integument, while in the clot group (figure (e)) only a thin layer of newly formed bone (red arrow) on small areas of connective tissue (CT) can be observed. Figures (b), (d), and (f) details of the previous figures showing the areas of new bone on a trabecular arrangement $\left(^{*}\right)$ in the positive control (PTFE) (figure (b)) and NR membranes (figure (d)). In the negative control (clot, figure (f)) the group bone formation $\left(^{*}\right)$ is restricted due to the adjacent competitor tissue (AT). Edge default $=$ dotted line. Objective of $4 \times$ and $10 \times$. Trichrome Masson.
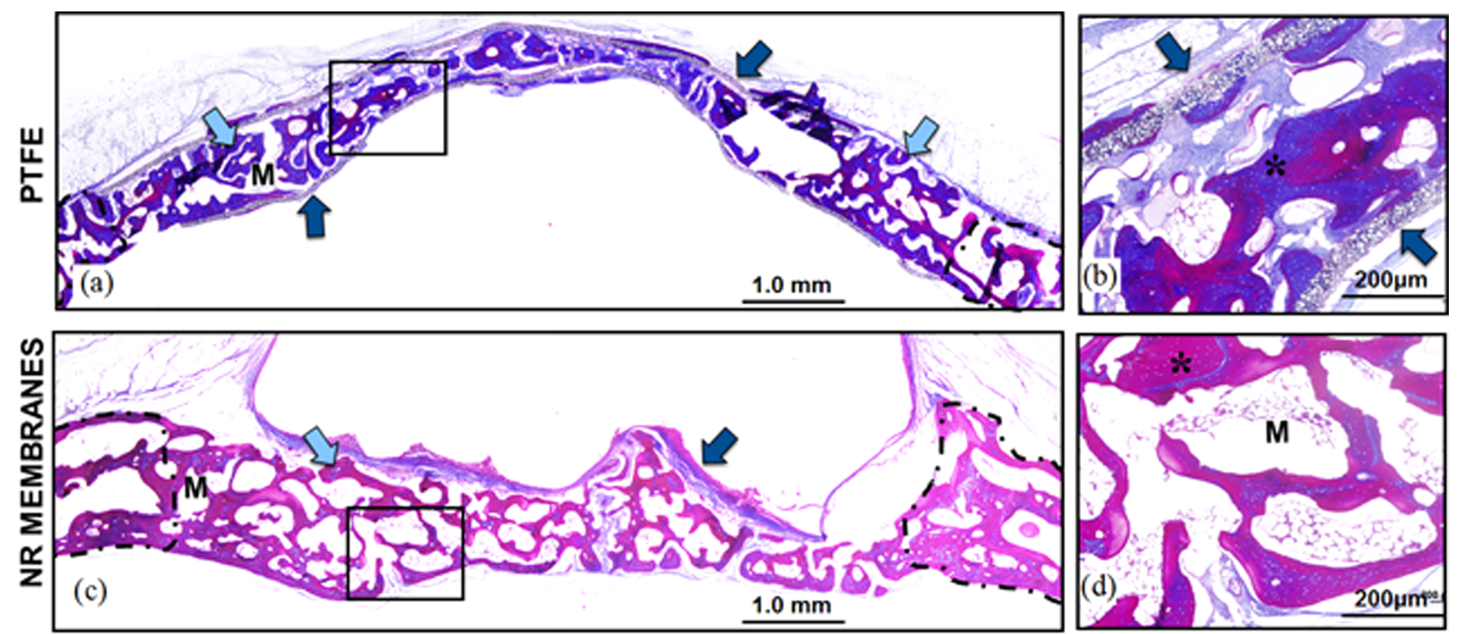

Figure 7. Photomicrographs of the evolution of the bone defect made in the calvaria of the rabbits treated with PTFE and latex membrane (figures (a)-(d)) for 90 days. Figures (a) and (c) widescreen aspect showing the total defect repair. Note in the repair of the groups treated with the PTFE membrane (figure (b)) and latex (figure (d)) to fill in for lots of lamellar bone trabeculae (blue arrow) interspersed with bone marrow (M). Figures (b), (d), and (f) show details of the previous figures showing the areas of the trabecular bone tissue arrangement $\left(^{*}\right)$ PTFE (figure (B)) and Latex (figure (F)). Edge default $=$ dotted line. Objective of $4 \times$ and $10 \times$. Trichrome Masson.

brasiliensis and Hancornia speciosa, even when stabilized in ammonia or sterilized by gamma irradiation [19].

The NR membranes presented here were produced from a non-ammoniated latex, which is essential to the compatibility presented here. Moc et al observed better adhesion of the L929 fibroblast on the NR prevulcanized using gamma irradiation or peroxide than in prevulcanized sulfur or in non-vulcanized high ammoniated latex [42]. Floriano et al studied the ammonia in different clones of Hevea brasiliensis and observed genotoxic and cytotoxic effects, as well as delays in wound healing in the ammoniated membranes, contrary to non-ammoniated membranes, whose IAN 873 and RRIM 600 clones showed in vitro bioactivity [5]. Almeida et al 


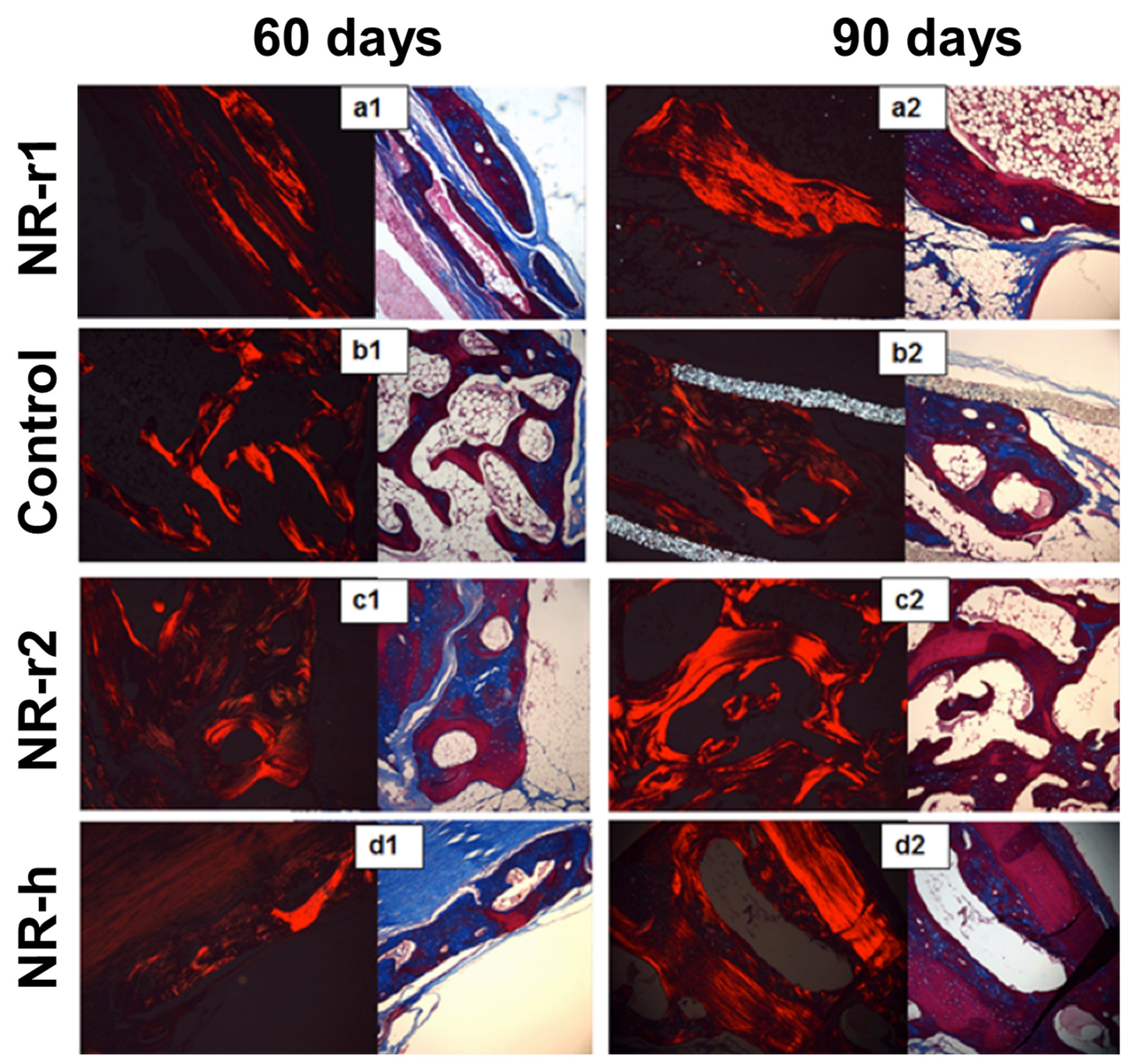

Figure 8. Histological images associated with polarized-light for: (a) the NR-r1 group; (b) the positive control group; (c) NR-r2; (d) NR-h. The images with (1) refer to the period of 60 days and (2) for 90 days after the defect creation.

Table 3. Results of histomorphometric analysis showing the average bone volume in the NR membranes groups and the positive control.

\begin{tabular}{lc}
\hline Experimental group & Average bone volume/field $( \pm$ s.d. $)$ \\
\hline NR-r1-60 days & $23,9 \pm 8,07^{\mathrm{a}}$ \\
NR-r1-90 days & $45,83 \pm 20,4^{\mathrm{c}}$ \\
NR-r2-60 days & $27,12 \pm 15,9^{\mathrm{a}}$ \\
NR-r2-90 days & $43,1 \pm 24^{\mathrm{c}}$ \\
NR-h-60 days & $25,08 \pm 5,17^{\mathrm{a}}$ \\
NR-h-90 days & $45,23 \pm 10,26^{\mathrm{c}}$ \\
PTFE-60 days & $26,02 \pm 16,8^{\mathrm{a}}$ \\
PTFE-90 days & $30,95 \pm 21,1^{\mathrm{b}}$
\end{tabular}

\footnotetext{
a No significant difference comparing all the groups during the 60 day testing period.

${ }^{\mathrm{b}} \mathrm{P}<0.05$ Significantly different from comparing all the groups during the 90 day testing period.

${ }^{c} P<0.001$ Significantly different from comparing all the groups during the 60 day testing period versus the 90 day testing period.
}

also observed the detrimental effect in cell survival with ammoniated Hancornia speciosa membranes [19].

All the NR membranes presented high surface porosity, as shown in the SEM micrographs (figure 3), where it is also possible to observe cells adhered to the surface. The cell adhesion in the NR membrane surface is shown as cells with a spread and flat morphology (figures 3(a) and (b)). Oh et al observed that membranes of poly(lactic-co-glycolic acid) PLGA/ F127 with a porosity of $40 \mu \mathrm{m}$ facing the bone defect can improve adhesiveness with bone, while $50 \mathrm{~nm}$ at the top prevented fibrous connective tissue invasion but permeated nutrients; Cho et al also observed lower bone regeneration to the polycaprolactone PCL/Tween 80 nanofiber mesh with smaller pores compared to the PLGA/F127 or PCL/PLA, and that even $50 \mathrm{~nm}$ pores permit the permeability of BSA (bovine serum albumin) [43, 44].

Following bone injury, a number of cellular and chemical events result in the regeneration of the bone tissue. Initially, the osteocytes produce an unmineralized bone matrix, and later, by means of specific chemical tracers, the mineralization of this tissue occurs [45]. The surface characteristics of the materials' important aspects, whether their topography, porosity, roughness, chemistry, or others factors, play an essential part in osteoblast adhesion on biomaterials. Thus, attachment, adhesion, and spreading belong to the first phase of cell/material interactions and the quality of this first phase will influence the cell's capacity to proliferate and to differentiate itself on contact 
with the implant [46]. All the NR membranes presented in this study showed excellent superficial adhesion cell due to their porous surface, as in the set shown in the SEM micrographs (figure 3). This fact corroborates the results in the in vivo tests. The results from radiography show that, after the 30 day period of implantation, the groups treated with NR-r1, 2 and NR-h membranes already had radiopaque regions on the edge of the created CSD, when compared with the positive and negative control groups, as can be seen in figures 4(a) and (b), and figure S1 from the supplementary data. This fact indicates that the membranes can speed up the process of bone regeneration, speeding up the mineralization of the connective tissue during the stage of bone formation. During the 60 and 90 day period, the groups treated with NR-r 1,2 and NR-h membranes showed larger and more homogeneous radiopaque regions than with the positive control, as can be observed in figures 1(c), (d), (f), and (g), and figure S1. This indicates that NR-r1,2 and NR-h membranes have greater potential for bone formation than PTFE membranes. When we compare the groups in which both NR-r1,2 and NR-h membranes were used with the negative control, it is possible to verify their great potential for osteogenesis induction, since during this testing period the negative control that received the fibrin clot showed no radiopaque area, indicating that there was no spontaneous bone regeneration (figures 4(c), (f), (c), and (h)), and figure S1. Only during the 90 day period is it possible to observe the beginning of new bone formation on the edges of the defects in the negative control (figure 4(h)). The results obtained in this study are in accordance with studies found in the literature, which confirm that the use of latex membranes in surgical processes for bone regeneration is adequate, since the barriers formed prevent or hinder the migration of cells incompatible with the new tissue to be formed, and promote osteogenesis. As expected from previous studies the animals treated with latex membranes showed better results than those treated with the PTFE membrane [7].

The CT analyses carried out during the 60 and 90 day periods showed similar results to radiography, where the groups treated with NR-r1 (figure 5(a)), NR-r2 (figure 5(b)) and NR-h (figure S2 from the supplementary data) membranes showed hyperdense laminae on the edges of the defects, which grew larger and more homogeneous during the experiment. The CT analyses of the positive control group, during the available periods, showed very thin, hyperdense, and small homogeneous laminae (figures 5(c) and (d) and figure (S2)), different from those observed in the groups treated with NR-r1,2 and NR-h membranes. This fact shows that the osteogenic potential of the NR membranes is superior to the positive controls. However, in the negative control group, the laminae are not observed in the CT images, since the CSD was not capable of regenerating itself spontaneously. When we compare the groups treated with NR-r1,2 and NR-h with the negative control, it was possible to verify the potential of these membranes in this type of application, as can be verified in figures 5(a), (b), (e), (f), and figure S2.

The analyses of bone density from the CT show that the bone density in the groups treated with NR$\mathrm{r} 1,2$ and NR-h was higher than in the control groups during all the testing periods. Moreover, the groups treated with NR-r2 and NR-h presented smaller bone density when compared with the groups treated with the NR-r1 membrane, but this difference was not statistically significant $P>0.05$ (figure 5(g)). Therefore, we can verify that there are no differences in bioactivity between the samples tested. During the 60 day period, the bone density corresponded to the D4 bone type formed by a thin layer of cortical bone covering the medullary bone with large trabeculae, that is to say, a more malleable bone. On the other hand, during the 90 day period, we verified in all the groups treated with NR-r1,2 and NR-h the presence of the D3 type bone, which is formed by a thin layer of cortical bone covering the medullary bone with small trabeculae. This is a bone of better quality and resistance, closer to the native bone present in the regions to the left and right of the CSD [47, 48]. Therefore, both Hevea brasiliensis clones present high bone regeneration potential and are suitable for use as biomaterials for bone repair. The same results were verified for Hancornia speciosa latex, indicating that it presents similar bone regeneration potential to that found in the Hevea brasiliensis samples.

The results of the bone density found lower bone density in the groups treated with NR- r2 and NR-h, when compared to groups treated with the NR-r1 membrane, but the difference was not statistically significant $P>0.05$ (figure 5(g)). So there are no differences in bioactivity between the samples tested. Both clones tested from Hevea brasiliensis have high potential for bone regeneration, and are suitable for bone regeneration. The same thing is seen for Hancornia speciosa, which presents potential for bone regeneration similar to that found in the samples of Hevea brasiliensis.

Our results confirm those found in the literature, verifying that the animals treated with NR showed significant improvement during the process of bone regeneration, and an increase in mature bone volume during all the periods of study up to 120 days. This result was strengthened by means of ESR analysis, which indicated a higher degree of bone mineralization in the group treated with NR [8].

From the histological analyses it was possible to verify that all the groups treated presented new bone during the first testing period, revealed by large areas marked in blue (Masson trichrome) (figures 6(a)-(f)). The use of polarized-light methods shows that the new bone is disorganized, which is a characteristic of primary bone [49], but organized lamellar bone is also observed in smaller proportions, showing the 
beginning of maturation of the newly formed bone (figures 8(a1), (b1), (c1), and (d1)). During the 90 day period, the groups treated with NR membranes have mature new bone (see the large red areas in figures 7 (c) and (d)). These bones are remarkably organized; they have a lamellar structure with Haversian canals (figures 8(a2), (c2), and (d2)), contrary to what was verified in the group treated with PTFE membranes, where, during the second testing period, there was no evidence of large regions of mature bone, which only appeared in small fragments, confirming the CT results (figures 7(a)-(b) and 8(b2)). During this testing period, the PTFE group presented lower bone density than the NR-treated groups, showing that there was no bone maturation. As shown in figures 6 and 7, all the NR-treated groups presented good osteoblastic activity, regions with osteoclastic activities, and large amounts of ossifying connective tissue during both testing periods. On the other hand, in the negative control group (clot), there was no new bone, only a large number of fibroblastic cells and regions with dense connective tissue during both the testing periods, as seen in figures 6(e) and (f), representative of the 2 testing period due its resemblance. These results are in accordance with the literature, proving that CSD cannot be repaired spontaneously [16].

Histomorphometric analyses showed that during the first testing period, all the treated groups showed similar bone volumes, although the group treated with NR-r1 showed a bone volume slightly lower than the other groups, but the difference was not statistically significant. During the second testing period, on the other hand, the groups treated with NR-r1,2 and NR-h presented a bone volume $67 \%$ higher than the group treated with PTFE, see table 3.

This result indicates that the NR-r1,2 and NR-h membranes are more efficient in the process of bone regeneration, promoting a bone formation of good quality, where it was possible to verify a large amount of well organized mature new bone at the end of this study. Both Hevea clones present the same bioactivity potential in the bone regeneration, and are highly suitable for this type of application, as can be seen in the excellent results presented in this paper. It was evident that the NR-h membranes are effective in the process of bone reparation, and their performance was very similar to the group treated with NR-r1,2. These results indicate that Hancornia speciosa latex is appropriate for this type of application, and we thus believe it to be a promising material for the production of biomaterials aiming at bone repair, in particular for patients with atopy to rubber tree latex (Hevea brasiliensis). Moreover, this latex is an easily accessible lowcost material, thus being a highly recommended material. Compared with other bone regeneration methods as allografts, the NR membranes' advantage of efficient bone regeneration and bone quality, do not transmit diseases and are biocompatible, which cannot occur with the allografts [50]. When compared with another methodology that utilizes Synthetic hydroxylapatite (tricalcium phosphate-TCP), the NR membranes present the advantage of promoting osteogenesis and bone regeneration through its bioactive components. On the other hand, TCP also fails to satisfy the standards set by those of autogenous bone because it does not have the organic, cellular component. To be effective in the process of bone regeneration, as with the synthetics, it must be placed in an osteogenic environment [51]. When compared with absorbable membranes, the NR membranes present numerous advantages such as occlusion, maintenance of adequate space for bone neoformation, osseointegration not requiring further surgery for removal of the implant site, unlike the absorbable membranes composed of polylactic acid, polygalactin 910, collagen, and dura mater. However, some membranes were associated with inflammatory reactions in the adjacent tissue or were quickly degraded by the enzymatic activity of macrophages and neutrophils. Absorbable membranes that are available are not able to maintain the appropriate space unless they have a favorable defect morphology [52].

\section{Conclusions}

The results of the physicochemical characterization show that both the NR membranes presented elastomeric behavior, with high elongation and a low Young's modulus, although the NR membrane from Hevea brasiliensis appeared to be stiffer than the NR membrane from Hancornia speciosa due to a higher Young's modulus, and more resistant with higher elongation and stress at rupture. In both NR membranes the stress-strain profile showed low stress at small strain, characteristic of an elastomer with a low degree of reticulation, followed by an increase in the stress at high deformation.

The FTIR results show two main differences between both NRL biomembranes, related to their composition. The Hancornia speciosa latex is known to possess higher amount of fatty acids, while Hevea brasiliensis have a higher protein content.

All the NR membranes presented high surface porosity, as noted in the SEM micrographs and cells adhered to the surface.

The results show that the NR-r1 and r2 membranes are effective in the process of bone repair, and prove superior to PTFE. No significant differences were found in the bioactivity of these two clones, both obtaining excellent results for this type of application. The same went for the NR-h membranes, presenting results very similar to NR-r 1 and $\mathrm{r} 2$.

The NR-r1,2 and NR-h membranes proved capable of promoting quality bone repair, evolving over time, and are thus highly recommended as biomaterials for bone repair. Moreover, these membranes also 
showed excellent applicability, elasticity, and resistance for application to bone defects.

The NR-h membrane can be used as an alternative to the other NR membranes, for possessing the same osteogenic potential, promoting satisfactory bone regeneration.

The FS proved to be efficient for this type of application; all the membranes remained well adhered to the bone surface, there being no case of detachment of the membranes during the whole study, neither were there negative responses in the regions where the sealant was applied.

\section{Acknowledgments}

Our thanks go to Professor Dr Joaquin Coutinho Netto (in memoriam) for his great contribution to the study and his understanding of the bioactive properties of latex; to Professor Dr Luis Fernando Barbisan, Professor Dr Sergio Luis Felisbino, and Msc. Ricardo Arantes for their assistance in the histologic, histomorphometric analyses; and to Heveatec for ceding the latex samples. The authors acknowledge the funding received through the UEG for the translation of this article, as well as the funding received through Coordenação de aperfeiçoamento de pessoal de nível superior-CAPES INCTMN/Nanobiomed, CAPES AUX-PE Toxinology, and FAPESP for the development of this research.

\section{References}

[1] O’Brien F J 2001 Biomaterials \& scaffolds for tissue engineering Mater. Today. 14 88-95

[2] Kokubo T and Takadama H 2006 How useful is SBF in predicting in vivo bone bioactivity? Biomaterials 29072915

[3] Dimitriou R, Jones E, McGonagle D and Giannoudis P 2011 Bone regeneration: current concepts and future directions BMCMed. 966

[4] Ereno C, Catanzaro S A G, Pasetto S, Herculano R D, Silva C P Graeff C F O, Tavano O, Baffa O and Kinoshita A 2010 Latex use as an occlusive membrane for guided bone regeneration J. Biomed. Mater. Res A 95A 932-9

[5] Floriano J F, Mota L S L S, Furtado E L, Rossetto V J V and Graeff C F O 2014 Biocompatibility studies of natural rubber latex from different tree clones and collection methods J. Mater. Sci.-Mater. Med. 25 461-70

[6] Neves-Junior W F P, Graeff C F O, Ferreira M, Mulato M, Bernardes M S and Coutinho-Netto J 2006 Elastic properties of natural rubber tubes produced by dip-coating J. Appl. Polym. Sci. $100702-7$

[7] Martins R, Kinoshita A M O, Nara T A and Guimarães S A C 2010 Comparative study of bone response guided tissue regeneration technique-macroscopic evaluation Full Dent. Sci. $1224-30$

[8] Herculano R D, Silva C P, Ereno C, Guimaraes S A C, Kinoshita A M O and Graeff C F O 2009 Natural rubber latex used as drug delivery system in guided bone regeneration (GBR) Mater. Res. 12 253-6

[9] Silva G A, Coutinho O P, Ducheyne P and Reis R L 2007 Materials in particulate form for tissue engineering applications in bone J. Tissue Eng. Regen. Med. 197-109

[10] Balabanian C A, Coutinho J N, Lamano C T L, Lacerda S A and Brentegani L G 2006 Biocompatibility of natural latex implanted into dental alveolus of rats J. Oral Sci. 48 201-5
[11] Ciapetti G, Stea S, Pizzoferrato A, Checchi L and Pelliccioni G A 1994 A latex membrane as an alternative device in the GTR technique: preliminary report on its biocompatibility J. Mate. Sci.- Mater. Med. 5 647-50

[12] Berthelot K, Lecomte S, Estevez I, Coulary-Salin B, Bentaleb A, Cullin C, Deffieux A and Peruch F 2012 Rubber elongation factor (REF), a major allergen component in Hevea brasiliensis latex has amyloid properties PloS One 7 1-12

[13] Thomazini J A, Mrué F, Lachat J J, Zaborowiski A C, Duran J H R, Ceneviva R and Coutinho-netto J 1997 Morpfological and biochemical characterization of a prosthesis manufactured from latex natural of Hevea brasiliensis for medical utilization Acta Microsc. 6 798-9

[14] Malmonge J A, Camilo E C, Moreno R M B, Mattoso L H C and McMahan C M 2009 Comparative study on technological properties of latex and natural rubber from Harconia speciosa gomes and Hevea brasiliensis J. Appl. Polym. Sci. 111 2986-91

[15] Mooney M P and Siegel M I 2005 Animal models for bone tissue engineering ed G Wnek and G Bowlin Encyclopedia of Biomaterials and Biomedical Engineering (New York: Dekker) pp 1-19

[16] Hollinger J O and Kleinschmidt C J 1990 The critical size defect as an experimental model to test bone repair materials J. Craniofac. Surg. 1 60-8

[17] Perka C, Schultzb O, Spitzer R S, Lindenhayn K, Burmester G R and Sittinger M 2000 Segmental bone repair by tissue-engineered periosteal cell transplants with bioresorbable fleece and fibrin scaffolds in rabbits Biomaterials 21 1145-53

[18] Rudin M and Weissleder R 2003 Molecular imaging in drug discovery and development Nat. Rev. Drug. Disc. 2 123-31

[19] Almeida L M, Floriano J F, Ribeiro T P, Magno L N, Mota L S L S, Mrué F N P, Melo-Reis P, Lino R S J, Graeff C F O and Gonçalves P J 2014 Hancornia speciosa latex for biomedical applications: physical and chemical properties, biocompatibility assessment and angiogenic activity J. Mater. Sci.- Mater. Med. 5 1-8

[20] Sampaio R L, Ranzani J J T, Brandao C V S, Thomazini-Santos A I, Barraviera B, Barraviera S R C S and Ginnini M J S M 2007 Use of fibrin glue derived from snake venom in the repair of deep corneal ulcers experimental study in dogs (Canis familiaris, Linnaeus 1758) J. Venom Anim. Toxins Incl. Trop. Dis. 27 857-73

[21] Machado E G, Issa J P M, Figueiredo F A T, Santos G R, Galdeano E A, Alves M C, Chacon E L, Ferreira Junior R S, Barraviera B and Cunha M R 2015 A new heterologous fibrin sealant as scaffold to recombinant human bone morphogenetic protein-2 (rhBMP-2) and natural latex proteins for the repair of tibial bone defects Acta Histochemica $117288-96$

[22] ISO 11.1372006 Review: Sterilization of Health Care Products

[23] Schmitz J P and Hollinger O J 1986 The critical size defect as an experimental model for craniomandibulofacial nonunions Clin. Orthop. 205 299-308

[24] Wang J and Glimcher M J 1999 Characterization of matrixinduced osteogenesis in rat calvarial bone defects: II. Origins of bone-forming cells Calcif. Tissue Int. 65 486-93

[25] Gosain A K, Santoro T D, Song L S, Capel C C, Sudhakar P V and Matloub H S 2003 Osteogenesis in calvarial defects: contribution of the dura, the pericranium, and the surrounding bone in adult versus infant animals Plast. Reconstr. Surg. 112515-27

[26] Barros L C, Ferreira R S J R, Barraviera S R C S, Stolf H O, Thomazini-Santos I A, Mendes-Giannini M J S, Toscano E and Barraviera B 2009 A new fibrin sealant from Crotalus durissus terrificus venom: applications in medicine J. Toxicol. Environ. Health B 12 553-71

[27] Barder D, Lignelli J, Smith B M and Bartee B K 2007 Using a dense PTFE membrane without primary closure to achieve bone and tissue regeneration J. Oral. Maxillofac. 65 748-52

[28] Taguchi Y, Amizuka N, Nakadate M, Ohnishi H, Fujii N, Oda K, Nomura S and Maeda T 2005 A histological evaluation for guided bone regeneration induced by a collagenous membrane Biomaterials 26 6158-66 
[29] Madhu K, Nair D M D and Li M S 2007 Digital and advanced imaging in endodontics: a review J. Endodontics 33 1-6

[30] Weibel E R 1963 Principles and methods for the morphometric study of the lung and other organs $L a b$. Investigation 12 131-55

[31] Brandt J Z, Silveira L T, Grassi T F, Anselmo-Franci J A, Fávaro W J, Felisbino S L, Barbisan L F and Scarano W R 2014 Indole-3-carbinol attenuates the deleterious gestational effects of bisphenol A exposure on the prostate gland of male F1 rats Reprod. Toxicol. 43 56-66

[32] Gelb D A 1999 Immediate implant surgery: ten-year clinicai overview Compendium Cont. Educ. Dent. $201185-92$

[33] Lopez-Soler R I, Brennan M P, Goyal A, Wang Y, Fong P, Tellides G, Sinusas A, Dardik A and Breuer C 2007 Development of a mouse model for evaluation of small diameter vascular grafts J. Surg. Res. 139 1-6

[34] Ferreira M, Mendonça R J, Coutinho Netto J and Mulato M 2009 Angiogenic properties of natural rubber latex biomembranes and the serum fraction of hevea Braz. J. Phys. 39564-9

[35] Valadares L F, Leite C A P and Galembeck F 2006 Preparation of natural rubber-montmorillonite nanocomposite in aqueous medium: evidence for polymer-platelet adhesion Polymer 47 672-8

[36] Rezende C A, Bragança F C, Doi T R, Lee L T, Galembeck F and Boué F 2010 Natural rubber-clay nanocomposites: mechanical and structural properties Polymer 51 3644-52

[37] Dall'Antonia A C, Martins M A, Moreno R M B, Mattoso H C, Job A E, Ferreira F C and Gonçalves P S 2006 Evaluation of clones of the raw natural rubber by standard test and dynamic mechanical properties Polímeros 16239-45

[38] Sansatsadeekul J and Sakdapipanich J 2006 Origin of Colloida Behavior of Natural Rubber Particles Mahidol University (http://2mtecorth/th/seminar/msativ/pdf/P14pdf)

[39] Amnuaypornsri S, Nimpaiboon A and Sakdapipanich J 2009 Role of phospholipids and proteins on gel formation and physical properties of NR during accelerated storage Kgk-Kaut Gummi Kunst. 62 88-92

[40] Amnuaypornsri S, Sakdapipanich J, Toki S, Hsiao B S, Ichikawa N and Tanaka Y 2008 Strain-induced crystallization of natural rubber: effect of proteins and phospholipids Rubber Chem. Technol. 81 753-66

[41] Amnuaypornsri S, Sakdapipanich J and Tanaka Y 2010 Highly purified natural rubber by saponificaion of latex: analysis of green and cured properties J. Appl. Polym. Sci. 1183524-31

[42] Mok K 1, Evans S D and Evans S W 2001 Cell adhesion on natural rubber latex films: influence of surface properties Rubb. Res. 4205-21

[43] Cho W J, Kim J H, Oh S H, Nam H H, Kim J M and Lee J H 2009 Hydrophilized polycaprolactone nanofiber meshembedded poly (glycolic-co-lactic acid) membrane for effective guided bone regeneration J. Biomed. Mater. Res. A 91 400-7

[44] Oh S H, Kim J H, Kim J M and Lee J H 2006 Asymmetrically porous PLGA/Pluronic F127 membrane for effective guided bone regeneration J. Biomater. Sci. Polym. Ed. 17 1375-87

[45] Punnett L and Wegman D H 2004 Work-related musculoskeletal disorders: the epidemiologic evidence and the debate J. Electromyogr. Kinesiol. 14 13-23

[46] Anselme K 2000 Osteoblast adhesion on biomaterials Biomaterials 21 667-81

[47] Cope J B and Samchukov M L 2001 Mineralization dynamics of regenerate bone during mandibular osteodistraction J. Oral. Maxillofac. Surg. 30 234-42

[48] Misch C E 2008 Contemporary Implant Dentistry 3rd edn (St. Louis: Mosby)

[49] Junqueira L C and Carneiro J 2013 Basic Histology 13th edn (New York: McGraw-Hill)

[50] Stevens B, Yang Y, Mohandas A, Stucker B and Nguyen T 2008 A review of materials, fabrication methods, and strategies used to enhance bone regeneration in engineered bone tissues J. Biomed. Mater. Res. B 85 573-82

[51] Hoexter D L 2002 Bone regeneration graft materials J. Oral Implantol. 28 290-4

[52] Monteiro A S, Macedo L G, Macedo N L and Balducci I 2010 Polyurethane and PTFE membranes for guided bone regeneration: histopathological and ultrastructural evaluation Med. Oral. Patol. Oral Cir. Bucal. 15 401-6 